\title{
Cardiovascular Drift during Training for Fitness in Patients with Metabolic Syndrome
}

\author{
AQIELIX MORALES-PALOMO ${ }^{1}$, MIGUEL RAMIREZ-JIMENEZ ${ }^{1}$, JUAN FERNANDO ORTEGA ${ }^{1}$, \\ JESUS GARCIA PALLARES ${ }^{2}$, and RICARDO MORA-RODRIGUEZ ${ }^{1}$ \\ ${ }^{1}$ Exercise Physiology Lab at Toledo, University of Castilla-La Mancha, SPAIN; and ${ }^{2}$ Human Performance and Sport Science \\ Lab, University of Murcia, SPAIN
}

\begin{abstract}
MORALES-PALOMO, F., M. RAMIREZ-JIMENEZ, J. F. ORTEGA, J. G. PALLARES, and R. MORA-RODRIGUEZ. Cardiovascular Drift during Training for Fitness in Patients with Metabolic Syndrome. Med. Sci. Sports Exerc., Vol. 49, No. 3, pp. 00-00, 2017. Purpose: The health benefits of a training program are largely influenced by the exercise dose and intensity. We sought to determine whether during a training bout of continuous versus interval exercise the workload needs to be reduced to maintain the prescribed target HR Methods: Fourteen obese $\left(31 \pm 4 \mathrm{~kg} \cdot \mathrm{m}^{-2}\right)$ middle-age $(57 \pm 8 \mathrm{yr})$ individuals with metabolic syndrome, underwent two exercise training bouts matched by energy expenditure (i.e., $70 \pm 5 \mathrm{~min}$ of continuous exercise [CE] or $45 \mathrm{~min}$ of interval exercise, high-intensity interval training [HIIT]). All subjects completed both trials in a randomized order. HR, power output (W), percent dehydration, intestinal and skin temperature ( $T_{\mathrm{INT}}$ and $\left.T_{\mathrm{SK}}\right)$, mean arterial pressure, cardiac output (CO), stroke volume (SV), and blood lactate concentration $\left(\mathrm{La}^{-}\right)$were measured at the initial and latter stages of each trial to assess time-dependent drift. Results: During the HIIT trial, power output was lowered by $30 \pm 16 \mathrm{~W}$ to maintain the target $\mathrm{HR}$, whereas a $10 \pm 11$ - W reduction was needed in the $\mathrm{CE}$ trial $(P<0.05)$. Energy expenditure, CO, and SV declined with exercise time only in the HIIT trial (15\%, 10\%, and 13\%, respectively). During HIIT, percent dehydration, $T_{\mathrm{INT}}$, and $T_{\mathrm{SK}}$ increased more than during the $\mathrm{CE}$ trial (all $P=0.001$ ). Mean arterial pressure and $\mathrm{La}^{-}$were higher in HIIT without time drift in any trial. Conclusion: Our findings suggests that ${ }_{2}$ results in mild power output reductions to maintain target HR, the increasingly popular HIIT results in reductions in power output, energy expenditure, and CO (21\%, $15 \%$, and $10 \%$, respectively). HIIT based on target HR may result in lower than expected training adaptations because of workload adjustments to avoid HR drift. Key Words: HEART RATE DRIFT, AEROBIC TRAINING, FITNESS, EXERCISE PRESCRIPTION, ENERGY EXPENDITURE, METABOLIC SYNDROME
\end{abstract}

$\mathrm{H}$ $\mathrm{R}_{\mathrm{L}}$ is a good index of exercise intensity up to levels close to maximum oxygen uptake $\left(\dot{\mathrm{V}}_{2 \max }\right)(16)$. The reliable lineal relationship of HR and exercise intensity and the availability of telemetric HR monitors have flourished the use of HR in training sessions. Thus, for endurance sports, the prescription of training loads is often based on the attainment and maintenance of a target HR (21). Detractors of monitoring exercise intensity by means of target HR argue that cardiovascular training adaptations (i.e., reductions in HR) require periodic readjustments of target HR values. However, data in endurance cyclists reveal that as training adaptations ensued, so does the workload to elicit the target HR. The progressive increase in workload to elicit the

Address for correspondence: Ricardo Mora-Rodriguez, Ph.D., Exercise Physiology Lab at Toledo, University of Castilla-La Mancha, Toledo 45071, Spain; E-mail: ricardo.mora@uclm.es.

Submitted for publication July 2016.

Accepted for publication October 2016.

0195-9131/17/4903-0000/0

MEDICINE \& SCIENCE IN SPORTS \& EXERCISE $_{\circledast}$

Copyright (C) 2016 by the American College of Sports Medicine

DOI: 10.1249/MSS.0000000000001139 target HR complies with the progressive overload training principle. This implies that a single pretraining determination of target $\mathrm{HR}$ (e.g., $90 \% \mathrm{HR}_{\max }=153 \mathrm{bpm}$ for an individual) is sufficient to prescribe training for the duration of a entire training program (23). Athletic training can be simplified not only by adjusting workloads based on target HR but also by training for improving fitness and health (39). In the HERITAGE family study with participants of a wide range in age, initial fitness level, and responses to training, the HR at a given percent of $\mathrm{VO}_{2 \max }$ was unaltered after 20 wk of a training program.

The other concern regarding the use of target HR to monitor exercise intensity is the occurrence of a common exercise phenomenon known as cardiovascular drift (i.e., CDV drift). CDV drift is the progressive increase in HR and the concomitant reduction in stroke volume (SV) that occur during prolonged fixed-load aerobic submaximal exercise $(35,36)$. The increases in HR during prolonged exercise, despite maintained workload, disrupt the single correspondence between HR and workload. CDV drift leaves exercise administrators with two choices, either to reduce the workload to maintain the target HR or to maintain the workload allowing HR to migrate above the HR target. To our knowledge, the consequences for training adaptations of each strategy have not been fully addressed in the scientific literature. 
In one study conducted on endurance-trained young individuals during exercise in the heat $\left(35^{\circ} \mathrm{C}\right), \mathrm{HR}$ was maintained at its target during the $45 \mathrm{~min}$ that the trial lasted (43). To keep HR constant, power output had to be lowered $37 \%$ (from 157 to $98 \mathrm{~W}) . \dot{\mathrm{VO}}_{2}$ declined by $24 \%$ because of the reduced metabolic demand from the lowered workload. Cardiac output (CO) declined by $20 \%$ and SV by $21 \%$. Thus, in this stressful environment, training by HR target could result in unplanned reductions in energy expenditure and cardiac work and possibly a delay in the metabolic and cardiovascular adaptations sought with training.

In the field of fitness programs to promote health, the existence of CDV drift has not been established. Mikus et al. (25) examined the effects of maintaining the target HR that elicited $50 \%$ of $\dot{\mathrm{VO}}_{2 \max }$ in a large group of postmenopausal women with overweight $(n=326)$. The purpose of the study was to determine whether workload reductions were required to maintain the target HR. They analyzed approximately 13,000 training sessions and concluded that in this population, they rarely have to reduce exercise intensity to maintain HR constant (i.e., only 1-4 bpm drift). However, the training was conducted in a low thermal strain environment (i.e., $20^{\circ} \mathrm{C}$ with fans and water available ad libitum) under a low metabolic demand (i.e., $\mathrm{CE}$ at $50 \% \dot{\mathrm{V}}_{2 \max }$ ).

High-intensity interval training (HIIT), a training mode originally used to improve athletic performance, has been quickly embraced in health fitness programs for being less time consuming and tedious than aerobic continuous training while producing similar health benefits. Although shorter, this training modality involves repeated short periods (30 s [24]; to $4 \mathrm{~min}$ [20]) of high-intensity exercise, which could lead to accumulated fatigue, transient hyperthermia, and sympathetic heart stimulation leading to CDV drift. To our knowledge, no study has addressed the cardiovascular and metabolic consequences of maintaining target HR during either a continuous moderate-intensity prolonged training bout in comparison with an HIIT session geared both to improve health status of the participants. In this study, we perform such experiment in overweight patients with metabolic syndrome enrolled in a health fitness exercise program. We did a full assessment of possible physiological variables linked to CDV drift (i.e., dehydration, $\mathrm{SV}$, core and skin temperature, blood pressure [BP], and blood lactate) that could account for HR drift during these two exercise training modes. Our hypothesis is that when using HIIT exercise bouts, workload may need to be reduced to maintain the target HR. The lowering of workload during HIIT bouts could deter the expected health related training adaptations.

\section{METHODS}

Participants. Fourteen middle-age $(57 \pm 8$ yr) obese subjects ( $n=11$ males and $n=3$ females) with a body mass

T1 index of $31 \pm 4 \mathrm{~kg} \cdot \mathrm{m}^{-2}$ (Table 1) and with metabolic syndrome completed this study. Metabolic syndrome was defined as the
TABLE 1. Anthropometric and cardiometabolic variables.

\begin{tabular}{lc}
\hline & Pretest \\
\hline Age and body composition & \\
Male/female & $11 / 3$ \\
Age $(\mathrm{yr})$ & $57 \pm 8$ \\
BMI $\left(\mathrm{kg} \cdot \mathrm{m}^{-2}\right)$ & $31 \pm 4$ \\
Fat $(\%)$ & $32 \pm 8$ \\
Fitness parameters & \\
$\dot{V}_{2 \text { peak }}\left(\mathrm{mL} \cdot \mathrm{kg}^{-1} \cdot \mathrm{min}^{-1}\right)$ & $30.2 \pm 8.1$ \\
$\mathrm{PO}_{\text {peak }}(\mathrm{W})$ & $225 \pm 60$ \\
$\mathrm{HR}_{\text {peak }}(\mathrm{bpm})$ & $167 \pm 12$ \\
\hline
\end{tabular}

Results as presented as mean \pm SD.

presence of three of the following five risk factors: elevated waist circumference, elevated BP, elevated fasting blood glucose, elevated triglycerides, or reduced HDL-C (1). Subjects were familiar with cycling as exercise mode because they were tested 2 months into a stationary cycling exercise program with a frequency of $3 \mathrm{~d} \cdot \mathrm{wk}^{-1}$ (24-28 sessions completed). Exclusion criteria included the use of medication known to affect $\mathrm{HR}$ response (i.e., beta blockers and $\mathrm{Ca}^{2+}$ antagonist), untreated thyroid, cardiovascular or renal disease, or any condition associated with exercise intolerance. All subjects provided written, witnessed, informed consent of the protocol approved by the Virgen de la Salud Hospital's Ethics Committee in accordance with the world medical association Declaration of Helsinki.

Preliminary testing. Peak aerobic capacity $\left(\mathrm{V}_{2} \mathrm{O}_{2 \text { peak }}\right)$ was assessed on an electronically braked cycle ergometer (Ergoselect 200; Ergoline, Germany) during graded exercise testing using indirect calorimetry (Quark b²; Cosmed, Italy) with 12-lead ECG monitoring (Quark T12, Cosmed). After $3 \mathrm{~min}$ of warm-up at $30 \mathrm{~W}$ for women and $50 \mathrm{~W}$ for men, workload was increased every minute ( $15 \mathrm{~W}$ women and $20 \mathrm{~W}$ men) until volitional exhaustion. Participants met or exceeded the criteria that indicated maximal effort with RPE $\geq 17, \mathrm{RER} \geq 1.1$, and $\mathrm{HR} \geq 85 \%$ of the maximal age predicted (2). The highest HR value obtained during the test was considered $\mathrm{HR}_{\text {peak }}$. Maximal power output values $\left(\mathrm{PO}_{\text {peak }}\right)$ and $\dot{\mathrm{V}}_{2 \text { peak }}$ are shown in Table 1 .

Experimental design. A repeated-measures crossover randomized design was used in which all subjects completed two trials, each one with a different exercise mode. In one occasion, subjects completed $45 \mathrm{~min}$ of high-intensity aerobic interval exercise (HIIT) consisting on pedaling for 10-min as warm-up $\left(70 \% \mathrm{HR}_{\text {peak }}\right)$ followed by $5 \times 4$-min intervals at $90 \%$ of $\mathrm{HR}_{\text {peak }}$ interspersed with a 3-min active recovery $\left(70 \% \mathrm{HR}_{\text {peak }}\right)$. In another occasion, subjects completed $70 \pm$ 5 min of CE test at $60 \% \mathrm{HR}_{\text {peak }}$. Exercise duration for the $\mathrm{CE}$ was individually calculated to result in similar energy expenditure than when performing the HIIT bout $(45 \mathrm{~min})$ for that subject. In turn, the energy to be expended during HIIT was estimated from the individual linear relationship between workload and $\dot{\mathrm{V}}_{2}$ from the initial graded exercise test. We recommend subjects to maintain a similar pedaling cadence in both trials (60-70 rpm). During exercise, HR was monitored every $5 \mathrm{~s}$ (Accurex coded; Polar, Kempele, Finland) by a researcher and workload adjusted to reach the desired target HR.

Experimental protocol. Tests were conducted at least $72 \mathrm{~h}$ after the last training bout, with subjects refraining from 
consumption of any stimulant that may have altered their cardiovascular response to exercise during the $24 \mathrm{~h}$ before exercise (alcohol, tobacco, coffee, tea, or herbal extracts). At least $72 \mathrm{~h}$ separated both trials. Each subject was tested in the morning at the same time of day to minimize the effects of circadian rhythm in HR and core temperature (22). Four hours before arriving at the laboratory, participants ingested a telemetric thermistor pill (CorTemp ${ }^{\mathrm{TM}}, \mathrm{HQ}$, Inc., Palmetto, FL) to allow us to measure intestinal temperature $\left(T_{\mathrm{INT}}\right)$ during exercise. Two hours before arrival to the laboratory, subjects ingested a light breakfast $(330 \mathrm{~mL}$ fruit milkshake and a pastry for a total of $624 \mathrm{kcal}$ and $68 \mathrm{~g}$ of carbohydrate). Upon arrival to the laboratory, subjects voided and nude body weight was recorded (Mettler Toledo Hawk, Columbus, OH). Urinespecific gravity $\left(\mathrm{U}_{\mathrm{SG}}\right)$ was measured to confirm euhydration $\left(\mathrm{U}_{\mathrm{SG}}<1.020\right.$ [37]). Then subjects dressed with shorts and a T-shirt and were instrumented with three ECG adhesive electrodes and an HR chest band to allow measurements of BP (Tango ${ }^{\mathrm{TM}}$; Suntech Medical Inc., Morrisville, NC) and HR (Accurex coded, Polar). Next subjects laid on a stretcher, and four temperature thermistors were attached to their skin to calculate average skin temperature $\left(T_{\mathrm{SK}}\right)$. Data between trials were compared at the (INIT) and at the (FINAL) of each protocol. Comparison times were chosen where accumulated energy expenditure was similar (i.e., isocaloric comparison) between trials. Thus, INIT comparison took place between 20 and $25 \mathrm{~min}$ of $\mathrm{CE}$ and between 10 and $17 \mathrm{~min}$ of HIIT. FINAL comparison took place between 60 and $65 \mathrm{~min}$ of CE and between 38 and $45 \mathrm{~min}$ of HIIT (Fig. 1). Measurements during HIIT were taken as the weighted mean value of the high-intensity bout ( $4 \mathrm{~min}$ at $90 \% \mathrm{HR}_{\text {peak }}$ ) and after the recovery bout ( $3 \mathrm{~min}$ at $70 \% \mathrm{HR}_{\text {peak }}$ ). At the end of each exercise trial, subjects toweled dry, and nude weight was measured again.

Metabolic measurements. During data collection periods (INIT and FINAL), $\mathrm{O}_{2}$ consumption $\left(\dot{\mathrm{VO}}_{2}\right)$ and $\mathrm{CO}_{2}$ production $\left(\mathrm{VCO}_{2}\right)$ were continuously measured using indirect calorimetry (Quark $b_{2}$, Cosmed) and values averaged. Energy expenditure was calculated from these data using Brouwer equations (3). At the beginning of each collecting period, a capillary blood sample was obtained by a finger prick in the right hand. The lactic acid concentration was analyzed using a hand held analyzer (Lactate Pro, Arkray, Japan).

Cardiovascular measurements. During the collection periods, BP was measured in the left arm (Tango ${ }^{\mathrm{TM}}$, Suntech Medical Inc.) in duplicate. Mean arterial pressure (MAP) was

\section{High Intensity Interval Training (HIIT)}

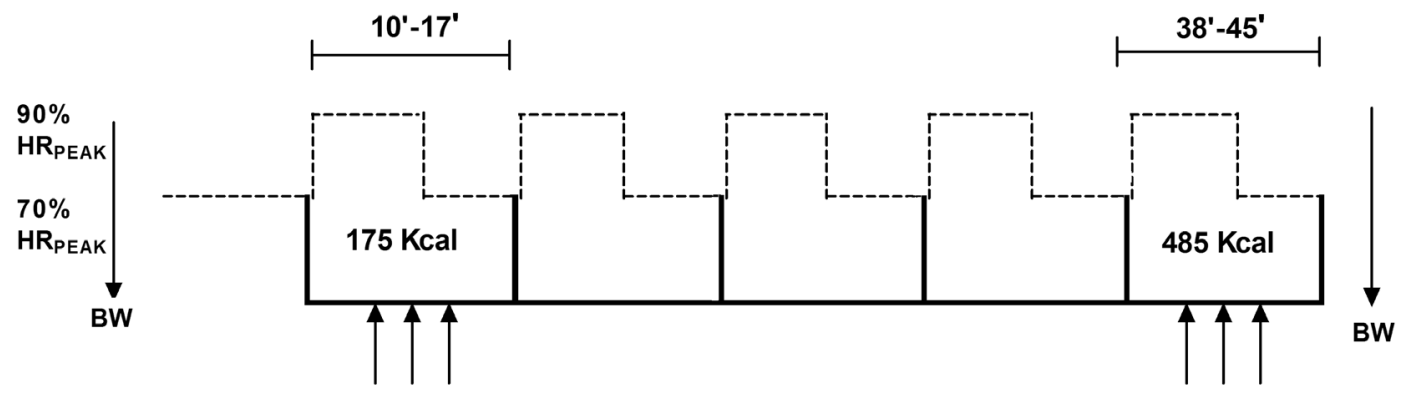

\section{Continuous Exercise (CE)}

\section{$45 \min$}
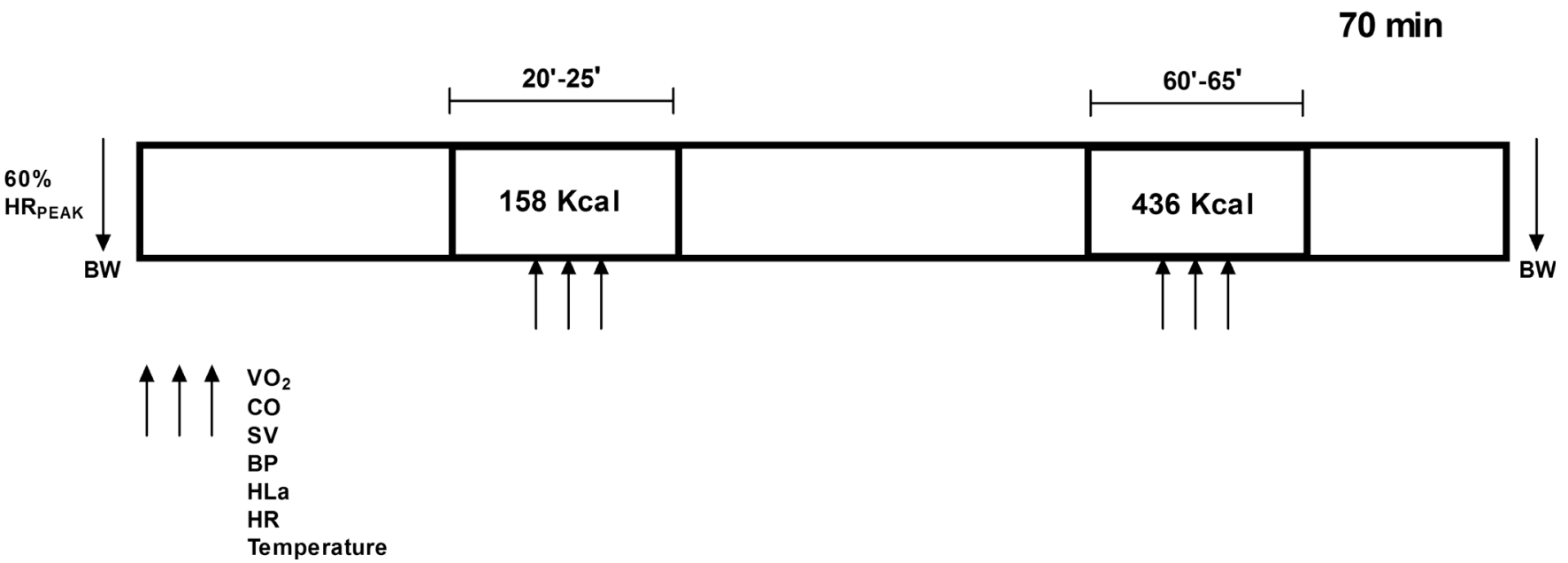

FIGURE 1-Experimental design. 
calculated as MAP $=[(\mathrm{SBP}-\mathrm{DBP}) / 2]+\mathrm{DBP} . \mathrm{HR}(\mathrm{RS} 400$, Polar) was averaged over the collection periods for each trial. In each measurement period, $\mathrm{CO}$ was measured in duplicate using the rebreathing technique (Innocor ${ }^{\mathrm{TM}}$; Innovision, Odense, Denmark). In brief, participants rebreathed a gas mixture of nitrous oxide $(0.5 \%)$ and sulfur hexafluoride $(0.1 \%)$ in oxygen, diluted with atmospheric air, from an anesthesia bag of size 3-6 L, depending on the participant's predicted vital capacity (33). SV was calculated by dividing the $\mathrm{CO}$ between HR. Systemic vascular resistance (SVR) was calculated by the following formula: $\mathrm{MAP} / \mathrm{CO} \times 80$, where 80 is a conversion factor to dynes $\cdot \mathrm{s}^{-1} \cdot \mathrm{cm}^{-5}$.

Thermoregulatory measurement. Whole-body percent dehydration was calculated by subtracting pre- from postexercise nude body mass and dividing by preexercise body weight. None of the participants urinated or ingested fluids during exercise, and thus no corrections were needed for these factors. Mean skin temperature $\left(T_{\mathrm{SK}}\right)$ was calculated using the formula of Ramanathan (34):

$$
T_{\mathrm{SK}}=0.3\left(T_{1}+T_{2}\right)+0.2\left(T_{3}+T_{4}\right),
$$

where $T_{1}, T_{2}, T_{3}$, and $T_{4}$ are temperatures measured at the chest, deltoid, thigh, and calf skin, respectively. Mean body temperature $\left(T_{\mathrm{B}}\right)$ was calculated from $T_{\mathrm{INT}}$ and $T_{\mathrm{SK}}$ with the formula of Colin et al. (7):

$$
T_{\mathrm{B}}=0.87 T_{\mathrm{INT}}+0.13 T_{\mathrm{SK}}
$$

Statistical analysis. Normality was evaluated by the Shapiro-Wilk test. Data collected overtime (INIT and FINAL) was analyzed using a two-way (treatment-by-time) repeatedmeasures ANOVA. After a significant $F$-test, pairwise differences were identified using Tukey's significance (HDS) post hoc procedure. Cohen's formula for effect size (ES [6]) was used, and the results were based on the following criteria: $>0.70$ large effect, $0.30-0.69$ moderate effect, and $\leq 0.30$ small effect. Pearson product-moment correlation coefficient was used to establish associations between the reductions in power output and other variables in the HIIT trial. All analyses were performed with the Statistical Package for the Social Sciences version 21 (SPSS Inc., Chicago, IL). Data presented as mean \pm SD. Statistical significance level was set at $P \leq 0.05$.

\section{RESULTS}

There were no significant different responses to any of the two exercise protocols between genders, and thus data were analyzed as a group $(n=14)$. In Figure 1, a layout of the two experimental trials is depicted. Because of the differences in exercise intensity between trials (lower in CE than HIIT), exercise time was extended in the $\mathrm{CE}$ trial to take measurements at comparable energy expenditure.

Experimental manipulation. During the HIIT trial, we were successful on clamping HR (controlled variable) to $90 \%$ of $\mathrm{HR}_{\text {peak }}$ and $70 \% \mathrm{HR}_{\text {peak }}$. During CE, HR target
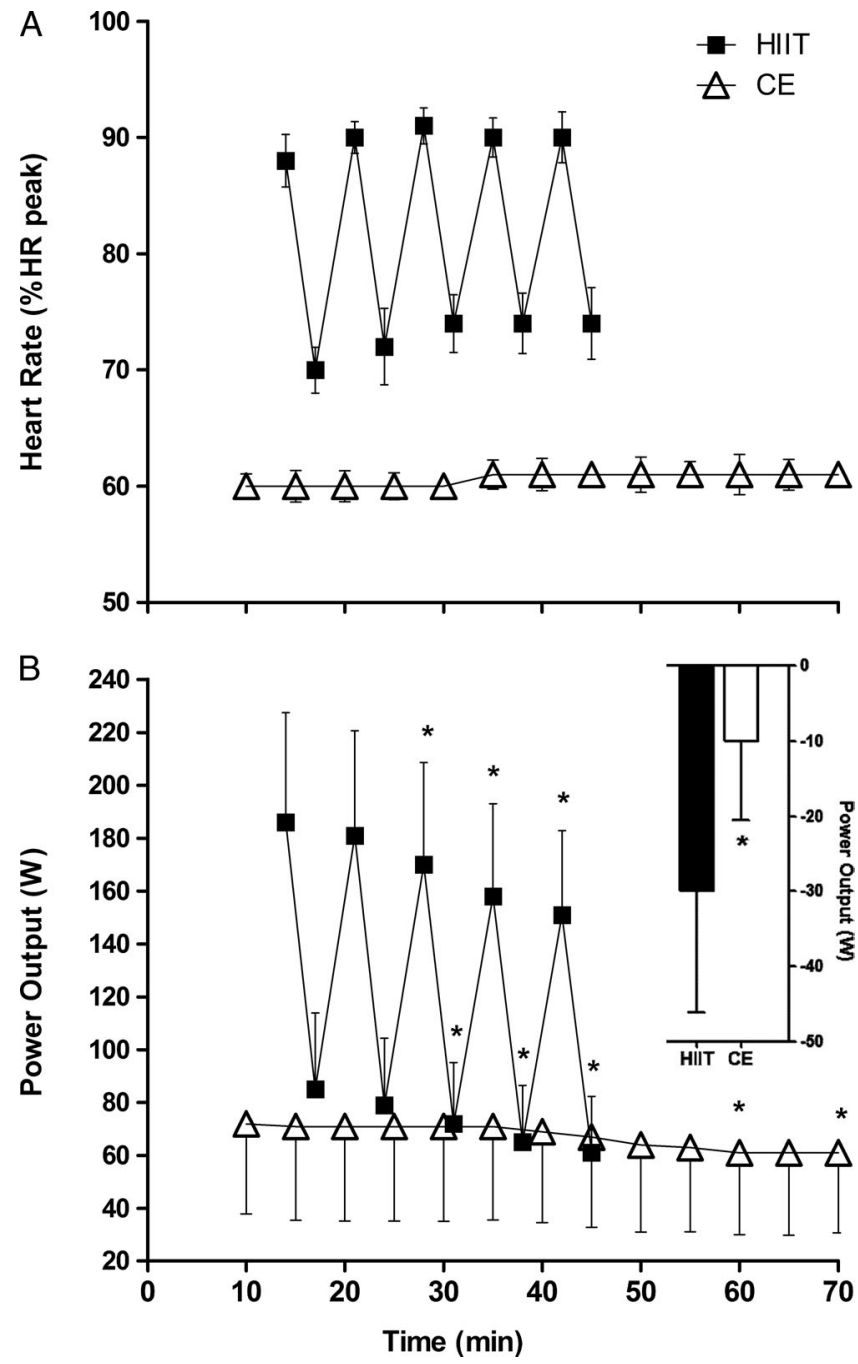

FIGURE 2-HR (\% maximum) (A) and power output (B) during a bout of CE or HIIT equaled by total energy expenditure $(\sim 460 \mathrm{kcal})$. Data are presented as mean \pm SD for 14 middle-age metabolic syndrome subjects. *Significant difference from the first time point for that trial $(P<0.05)$

HR and workloads were different between trials with higher values in the HIIT than $\mathrm{CE}$ trial $(P=0.001$; Figs. $2 \mathrm{~A}$ and $\mathrm{B})$. To maintain the target HR during the HIIT trial, researchers ought to reduce exercise workload by $30 \pm 16 \mathrm{~W}$ in the HIIT trial $(143 \pm 35$ to $113 \pm 27 \mathrm{~W}, \mathrm{ES}=0.96, P=0.001)$ and by $10 \pm 11 \mathrm{~W}$ in the $\mathrm{CE}$ trial $(71 \pm 36$ to $61 \pm 31 \mathrm{~W}, \mathrm{ES}=$ $0.31, P=0.003)$. The magnitude of reduction in workload was larger in the HIIT than that in the CE trial (insert of Fig. 2B).

Metabolic measurement. As design, energy expended (kcal accumulated) was similar in HIIT and CE at the first time comparison (i.e., INIT; $175 \pm 32$ vs $158 \pm 43 \mathrm{kcal}$ ) and at the last comparison (i.e., FINAL; $485 \pm 88$ vs $436 \pm 125 \mathrm{kcal}$; Fig. 3B). Accordingly, with the higher exercise intensity during HIIT, the rate of energy expenditure $\left(\mathrm{kcal} \cdot \mathrm{min}^{-1}\right)$ was higher during HIIT than during the CE trial $(P<0.001$; Fig. 3A). The rate of energy expenditure was maintained from INIT to FINAL in the CE trial $\left(6.3 \pm 1.7\right.$ to $6.3 \pm 1.7 \mathrm{kcal} \cdot \mathrm{min}^{-1}$, 
$\mathrm{ES}=0.008, P=0.934$; Fig. 3A). However, because of the 30-W reduction in workload during HIIT, there was a reduction in the rate of energy expenditure from INIT to FINAL (12.2 \pm 2.3 to $10.4 \pm 1.9 \mathrm{kcal} \cdot \mathrm{min}^{-1}, \mathrm{ES}=0.86, P=0.001$; Fig. $3 \mathrm{~B}$ ). Capillary blood lactate was higher during HIIT than during $\mathrm{CE}$ at the beginning (i.e., INIT $11 \pm 4$ vs $5 \pm 4 \mathrm{mmol} \cdot \mathrm{L}^{-1}$, respectively, $P=0.029$ ) and end of the trials (i.e., FINAL $12 \pm$ 4 vs $3 \pm 1 \mathrm{mmol} \cdot \mathrm{L}^{-1}$, respectively, $P=0.012$ ). With exercise time, blood lactate remained at similar concentrations in both trials (no time drift effect).

Cardiovascular measurement. There was no difference in $\mathrm{CO}$ among trials either in the beginning (INIT; $P=$ 0.102 ) or end of the trials (FINAL; $P=0.799$ ). Only during HIIT was $\mathrm{CO}$ reduced from beginning to the end of exercise $\left(12.6 \pm 2.9\right.$ INIT to $11.4 \pm 3.0 \mathrm{~L} \cdot \mathrm{min}^{-1}$ FINAL; $P=0.003, \mathrm{ES}=$ $0.41)$. In the $\mathrm{CE}$ trial, $\mathrm{CO}$ was maintained during the entire trial $\left(11.2 \pm 3.9\right.$ INIT to $11.5 \pm 2.7 \mathrm{~L} \cdot \mathrm{min}^{-1}$ FINAL; $P=$ $0.658, \mathrm{ES}=0.11$; Fig. $5 \mathrm{~A}$ ). $\mathrm{SV}$ was lower in the HIIT trial than that in the $\mathrm{CE}$ at the beginning and end of exercise $(P=$ 0.037 and 0.001 , respectively). With time of exercise, SV was reduced in the HIIT trial (INIT $99 \pm 23$ to $82 \pm 20 \mathrm{~mL} \mathrm{bt}^{-1}$ FINAL; $P=0.001$, ES $=0.64$ ), whereas during the $\mathrm{CE}$ trial, $\mathrm{SV}$ was maintained (INIT $115 \pm 37$ to $118 \pm 26{\mathrm{~mL} \cdot \mathrm{bt}^{-1}}^{-1}$ FINAL; $P=0.071, \mathrm{ES}=0.773$; Fig. $5 \mathrm{~B}$ ). MAP was lower in $\mathrm{CE}$ than HIIT $\left(P=0.001\right.$; Fig. $\left.{ }_{2} \mathrm{C}\right)$. Time of exercise did not affect BP that was maintained from INIT to FINAL in the $\operatorname{HIIT}(127 \pm 12$ to $124 \pm 17 \mathrm{~mm} \mathrm{Hg}, P=0.426$, ES $=0.20)$ and CE trials ( $97 \pm 7$ to $98 \pm 9 \mathrm{~mm} \mathrm{Hg}, P=0.250, \mathrm{ES}=0.18$; Fig. 5 C). When we calculated systemic vascular resistance (i.e., MAP/ $\mathrm{CO}$ ), values were similar between trials with a tendency to increase with time of exercise in HIIT $(1.1 \pm 1.7)$ and to decrease in CE $(-0.7 \pm 2.9)$.

Thermoregulatory measurement. Percent dehydration measured from body weight losses with exercise was larger in the HIIT than that in the CE trial $(0.85 \% \pm 0.3 \%$ vs $0.55 \% \pm$ $0.2 \%$, respectively, $P=0.001$, $\mathrm{ES}=1.15$ ). At the beginning of exercise (i.e., INIT), there was no difference in intestinal temperature $\left(T_{\mathrm{INT}}\right)$ between trials. However, with exercise time, there was an increase in $T_{\mathrm{INT}}$ in the HIIT $\left(37.1^{\circ} \mathrm{C} \pm 0.5^{\circ} \mathrm{C}\right.$ to $37.9^{\circ} \mathrm{C} \pm 0.6^{\circ} \mathrm{C}, P=0.001$, $\mathrm{ES}=1.53$ ), whereas the increase during $\mathrm{CE}$ did not reach statistical difference $\left(36.9^{\circ} \mathrm{C} \pm 0.3^{\circ} \mathrm{C}\right.$ to $\left.37.2^{\circ} \mathrm{C} \pm 0.6^{\circ} \mathrm{C}, P=0.06\right)$ trials. The magnitude of increase was higher in the HIIT trial than that in the $\mathrm{CE}$ trial $\left(0.81^{\circ} \mathrm{C} \pm\right.$ $0.4^{\circ} \mathrm{C}$ vs $0.38^{\circ} \mathrm{C} \pm 0.4^{\circ} \mathrm{C}, P=0.003$, Fig. 5A). Skin temperature $\left(T_{\mathrm{SK}}\right)$ was higher in the HIIT than that in the $\mathrm{CE}$ trial at the beginning of exercise (INIT; $32.4^{\circ} \mathrm{C} \pm 0.9^{\circ} \mathrm{C}$ vs $31.6^{\circ} \mathrm{C} \pm$ $0.9^{\circ} \mathrm{C}, P<0.001$; Fig. $\left.5 \mathrm{~B}\right) . T_{\mathrm{SK}}$ increased with time of exercise only during the HIIT trial $\left(32.4^{\circ} \mathrm{C} \pm 0.9^{\circ} \mathrm{C}\right.$ to $33.7^{\circ} \mathrm{C} \pm$ $0.6^{\circ} \mathrm{C}, P<0.001$, ES $=1.83$; Fig. $5 \mathrm{~B}$ ), whereas no increase in $T_{\mathrm{SK}}$ was present with exercise time in the $\mathrm{CE}$ trial $\left(31.6^{\circ} \mathrm{C} \pm\right.$ $0.9^{\circ} \mathrm{C}$ to $\left.31.7^{\circ} \mathrm{C} \pm 1.2^{\circ} \mathrm{C}, P=0.778, \mathrm{ES}=0.06\right)$. Therefore, calculated body temperature $\left(T_{\mathrm{B}}\right)$ was higher in the HIIT than that in the CE trial at the beginning and end of the trials $(P=$ 0.006). Although with exercise time $T_{\mathrm{B}}$ increased in both trials, the increase was larger in the HIIT than that in the $\mathrm{CE}$ trial $\left(0.87^{\circ} \mathrm{C} \pm 0.4^{\circ} \mathrm{C}\right.$ to $0.33^{\circ} \mathrm{C} \pm 0.4^{\circ} \mathrm{C}, P<0.001$; Fig. $\left.5 \mathrm{C}\right)$.
Correlations. The reductions in power output during HIIT were correlated with the percent dehydration $(r=-0.528, P<$ $0.05)$, but it did not reach statistical significance with the increases in $T_{\mathrm{SK}}(r=0.042, P=0.881), T_{\mathrm{INT}}(r=-0.193, P=$ $0.512)$, or MAP $(r=-0.111, P=0.705)$.

\section{DISCUSSION}

We conducted this study to determine whether CDV drift and its main manifestation, HR drift, take place during exercise training to promote health in a sample of middle-age participants with obesity and metabolic syndrome (1). In most adult fitness facilities, calibrated ergometers are not available because of their elevated maintenance costs and calibration requirements. Exercise intensity is then typically prescribed based on HR as a proxy of workload on account of the linear relationship between these two physiological variables (16) during submaximal workloads. However, CDV drift upset this parallelism elevating HR for a given workload (21). Our goal in this study was to ascertain if workload ought to be reduced in exercise bouts typically used during a health promoting training program (continuous or interval exercise type) to maintain the prescribed target HR. Furthermore, if workload needs to be reduced to avoid CDV drift, we sought to determine the magnitude of this reduction to gauge the consequences for the metabolic and cardiorespiratory training stimulus. We should consider that one of the main reasons for subjects to enroll in a health-oriented exercise program is to increase energy expenditure and fat oxidation to incur in negative energy balance and promote body fat loss (19). We found that to maintain the HR target, workload ought to be reduced by $21 \%$ (i.e., $30 \mathrm{~W}$ ) during a bout of intense interval exercise. Consequently, energy expenditure and $\mathrm{CO}$ were reduced during interval exercise (15\% and $10 \%$, respectively), curtailing the planned metabolic and cardiovascular training stimulus.

CDV drift is the topic of a fair amount of published studies and reviews $(8,42)$. Most of these studies are geared to understand the mechanisms behind this physiological event $(13,41)$ and its relationship with other physiological parameters (i.e., $\dot{\mathrm{V}} \mathrm{O}_{2 \max }[4,43]$ ), dehydration (17), exercise mode (44), or with exercise performance (31). All the cited studies were conducted in young healthy endurance-trained individuals, whereas one study stands alone in exploring the incidence of CDV drift when exercising for health purposes. This study (25) conducted in a large sample of overweight postmenopausal women (i.e., $n=326$, part of the larger DREW study) finds a very low incidence of CDV drift $(<1 \%)$ when training for health. Exercise training intensity and duration in that study was in the lower end of the American College of Sports Medicine prudent recommendations for exercise in deconditioned adults (i.e., $30-90 \mathrm{~min}$ at $50 \%$ of $\dot{\mathrm{V}} \mathrm{O}_{2 \text { peak }}$ [14]). However, in the last decade, the use of a training mode reserved for improving athletic performance (i.e., HIIT) has spread following the findings that HIIT elicits similar or larger health benefits than moderate CE mode in healthy sedentary $(15,29)$ and obese patients with metabolic syndrome $(26,40)$. Aware of 
the increased use of HIIT for promoting health, we studied CDV drift not only during a constant exercise bout (70 min at $60 \% \mathrm{HR}_{\text {peak }}, \mathrm{CE}$ trial) but also during an isocaloric bout of HIIT (45 min at $70 \%-90 \% \mathrm{HR}_{\text {peak }}$, HIIT trial).

Despite the isocaloric matching of the exercise trials, blood lactate concentration, the rate of energy expenditure (Fig. 3A), MAP (Fig. ${ }_{5}$ C), and body temperatures (Fig. 5) were higher in the more intense trial (i.e., HIIT). Our data allow us to analyze how variables drifted with exercise duration in both trials. The exercise intensity during our $\mathrm{CE}$ trial $\left(60 \% \mathrm{HR}_{\mathrm{MAX}}\right.$, $48 \% \dot{\mathrm{VO}}_{2 \text { peak }}$ ) matches the one used by Mikus and coworkers ( $\mathrm{CE}$ at $\left.50 \% \mathrm{VO}_{2 \text { peak }}[25]\right)$. In our case, during the $\mathrm{CE}$ trial, to maintain the target HR, workload was slightly lowered during the last stages of exercise (i.e., $10 \mathrm{~W}$ at 60-70 min of exercise; Fig. 2B). The slight but significant reduction in workload did not affect $\mathrm{VO}_{2}$ or $\mathrm{CO}$, and thus CDV drift had no incidence on the metabolic or cardiovascular demands of this training mode (i.e., continuous prolonged moderate intensity). By contrast, the marked reductions in workload during the $45 \mathrm{~min}$ of HIIT (i.e., $30 \mathrm{~W}$ ) lowered $\mathrm{VO}_{2}$ and CO. Consequently, energy expenditure decreased approximately $2 \mathrm{kcal} \cdot \mathrm{min}^{-1}$, and the heart pumped $1.2 \mathrm{~L} \cdot \mathrm{min}^{-1}$ less blood from the beginning to the end of the exercise bout (Figs. 3A and 4A). These numbers could seem negligible but when multiplied by a typical training program of 45 min per bout, three sessions per week during $16 \mathrm{wk}$ (26), they amount to a relevant reduction in energy expenditure and cardiac work.

Results from the dose-response to exercise (i.e., DREW study) reveal that the improvements in cardiorespiratory fitness (i.e., $\dot{\mathrm{V}}_{2 \max }$ ) of a 6-month training program in overweight women are intimately linked to the energy expenditure induced by training (10). Increasing energy expenditure with exercise from 8 to $12 \mathrm{kcal} \cdot \mathrm{kg}^{-1} \cdot \mathrm{wk}^{-1}$ (50\% increase) results in a $2.2 \%$ increase in $\dot{\mathrm{V}}_{2 \max }$. In this context, our finding of a $15 \%$ reduction in energy expenditure due to HR drift during HIIT may diminish the gains in cardiorespiratory fitness of a fitness program. However, renouncing to maintain target HR and leaving HR to drift up could result in overdue fatigue and reduce subject adherence to a training program (32). Even endurance-trained subjects volitionally lower their power output when performing in a hot environment to prevent undue HR drift (31). Thus, in our less conditioned population, even larger reductions in power output are expected to prevent HR drift. In our case, can-state that the expected benefits of a health-oriented HIIT program, with intensity controlled by target HR, should be rebated.

In young, healthy individuals, it is well established that exercising in a hot environment $\left(35^{\circ} \mathrm{C}\right.$ vs $\left.20^{\circ} \mathrm{C}\right)$ reduces aerobic performance either when measured by time to exhaustion (30) or by self-selected intensity during a time trial (31). During submaximal exercise in a hot environment (i.e., $35^{\circ} \mathrm{C}$ [43]), the prevention of $\mathrm{HR}$ drift required an important reduction in power output that resulted in $24 \%$ lowering of oxygen consumption and energy expenditure, similarly to what we currently report with our obese, deconditioned subjects. We conducted our testing in a thermoneutral environment $\left(24^{\circ} \mathrm{C}\right)$
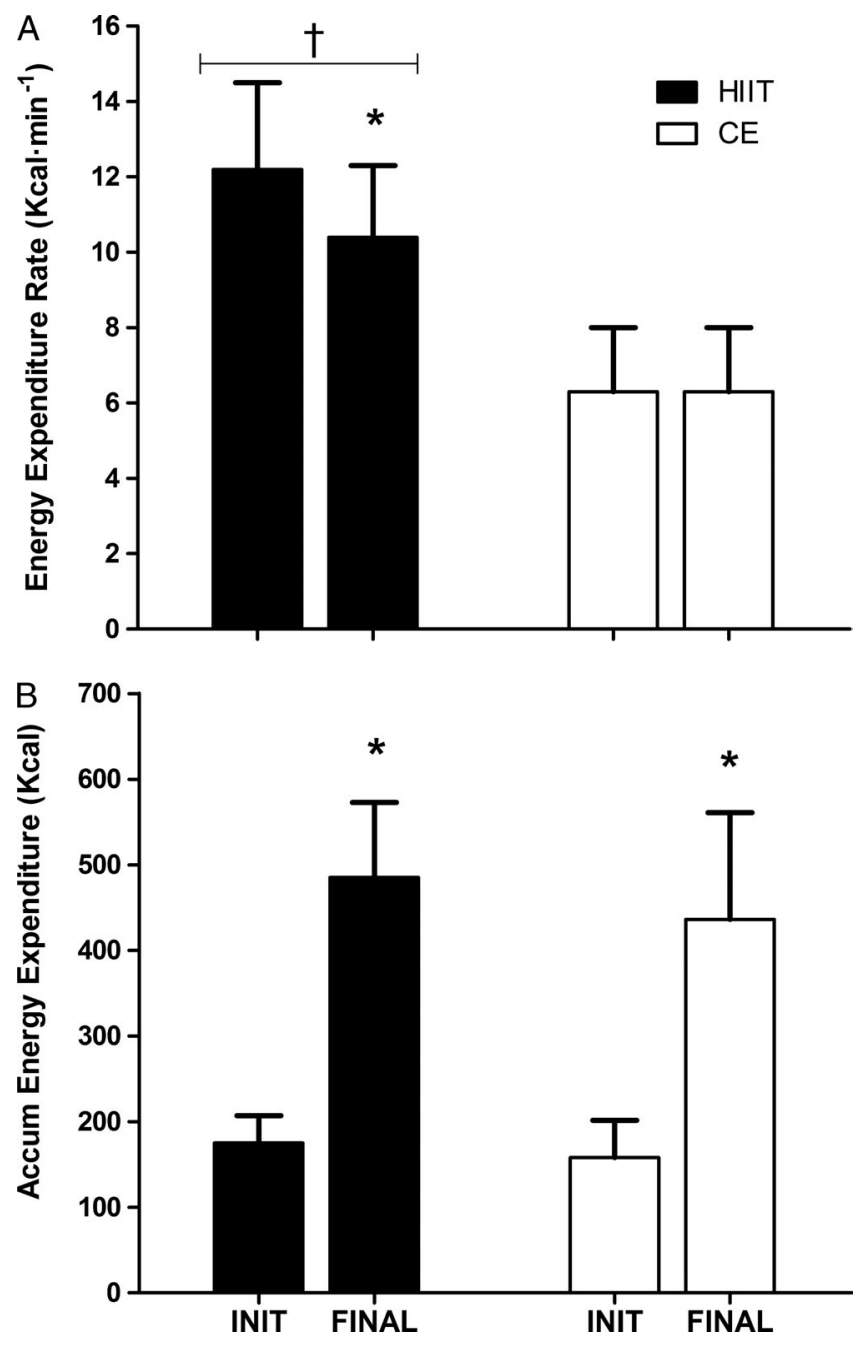

FIGURE 3-Energy expenditure rate (A) and accumulated energy expenditure (B) during a bout of CE or HIIT equaled by total energy expenditure. Data are presented as mean \pm SD for 14 middle-age metabolic syndrome subjects. *Significant difference between the INIT and the FINAL time point for that trial $(P<0.05)$. $†$ Significant difference between trials (HIIT vs $\mathrm{CE} ; \boldsymbol{P}<0.05$ ).

and monitored that participants were euhydrated $\left(\mathrm{U}_{\mathrm{SG}}<\right.$ 1.020 ) when starting the exercise bouts. Despite these favorable conditions to dissipate heat, during HIIT, a 21\% reduction in power output was required to maintain HR. When we correlated the increases in temperature (i.e., $T_{\mathrm{SK}}, T_{\mathrm{INT}}$ and $T_{\mathrm{B}}$ ) during HIIT with the reductions in power output, no clear association emerged. However, the lowering of power output was significantly correlated with the percent dehydration. It seems then that the more subjects dehydrated (i.e., higher sweat rate), the more power output needed to be reduced to maintain HR. Profuse sweating during exercise lowers blood volume (17), which may signal baroreceptors to increase HR to maintain BP (i.e., Fig. 5C $_{\mathbf{L}}$ [35]). This suggests that heavy sweaters may F5 be the ones lowering more power output and thus delaying training adaptations.

Experiments using cardioselective beta-adrenergic blockade $(\beta 1$ blocker $[13,41])$ have attempted to dissociate the reduction in $\mathrm{SV}$ that concomitantly occurs with the elevations 


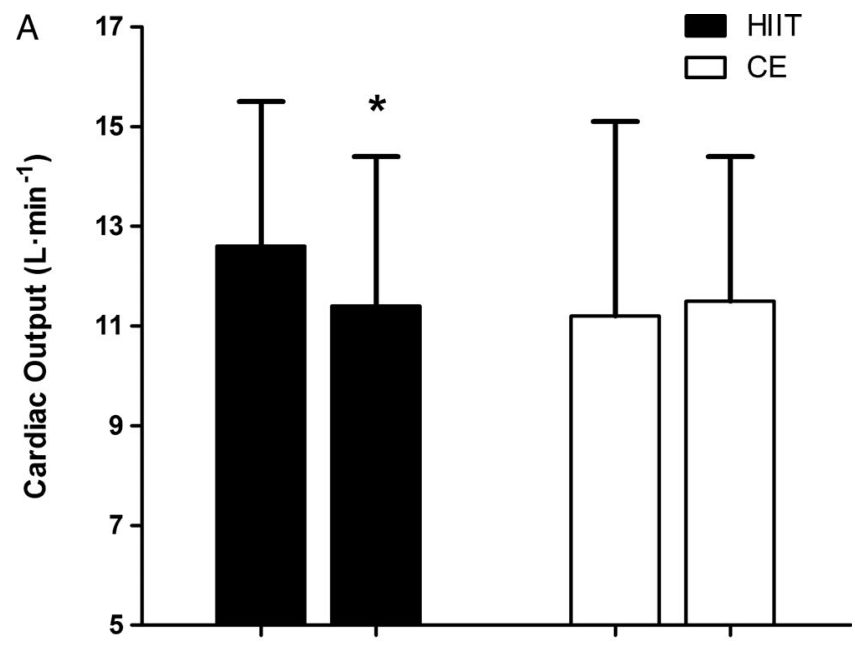

increased sinoatrial node temperature (18) and sympathetic cardiac stimulation (28). We observed that $T_{\mathrm{SK}}$ and $T_{\mathrm{INT}}$ were elevated in the HIIT in comparison with CE already at the first stages of exercise (i.e., INIT; Fig. 5A and B), which may explain the higher drive during the HIIT trial to increase HR and thus the larger reduction in power output needed to prevent it in comparison with the CE trial. On the other hand, the
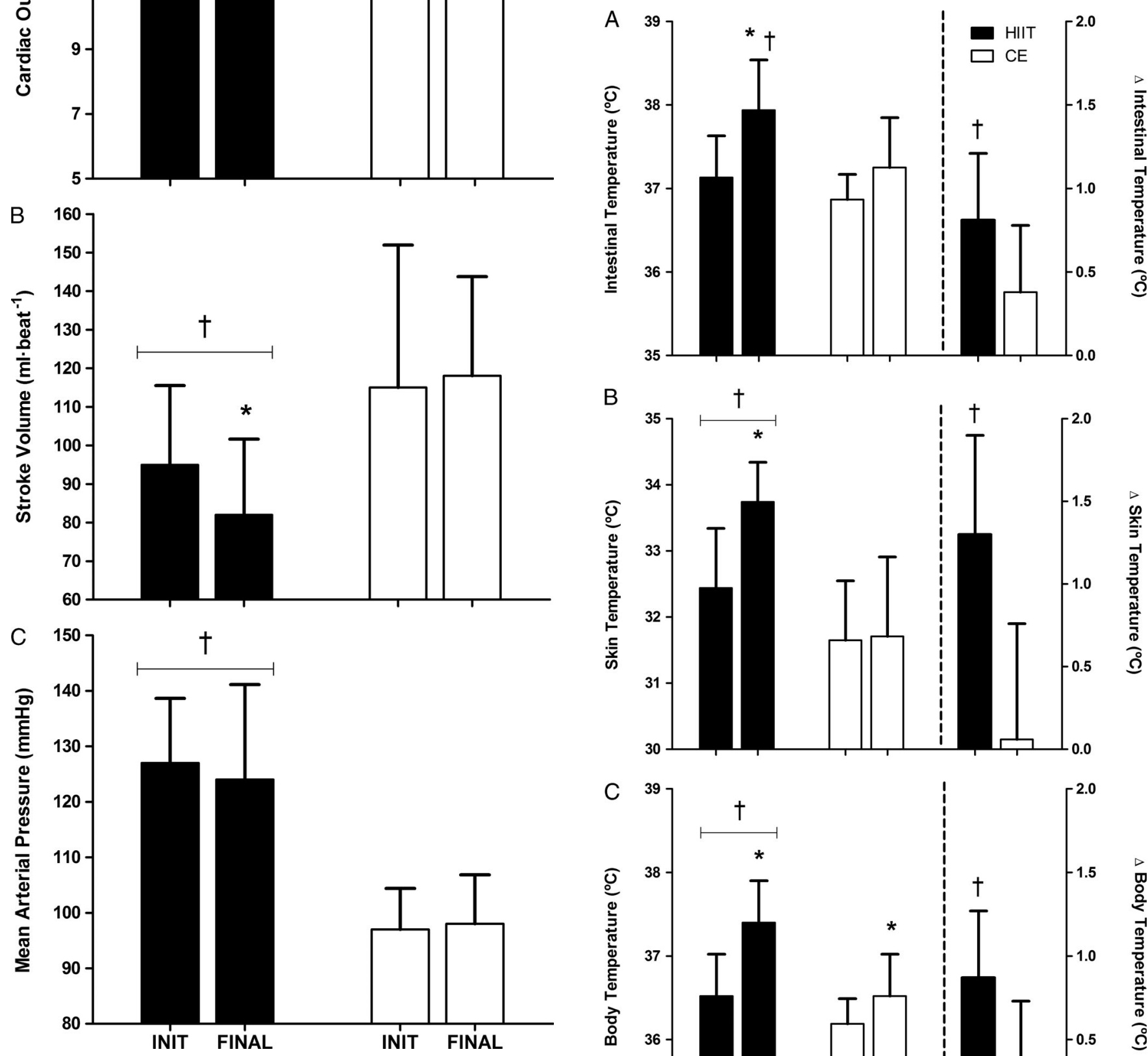

FIGURE 4-CO (A), SV (B), and MAP (C) during a bout of CE or HIIT equaled by total energy expenditure. Data are presented as mean \pm SD for 14 middle-age metabolic syndrome subjects. *Significant difference between the INIT and the FINAL time point for that trial $(P<0.05)$. $\dagger$ Significant difference between trials (HIIT vs CE; $\boldsymbol{P}<0.05$ ).

in HR during CDV drift. These studies revealed that the HR drift may be influenced by reduced central venous pressure signaling baroreceptors to increase HR (35) but also by

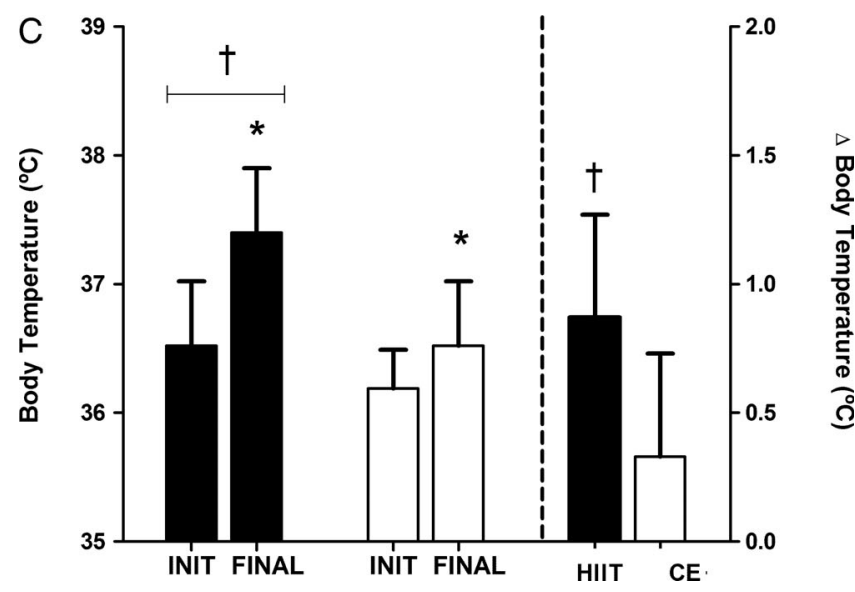

FIGURE 5-Intestinal (A), skin (B), and body temperatures (C) during a bout of $\mathrm{CE}$ or HIIT equaled by total energy expenditure. Data are presented as mean \pm SD for 14 middle-age metabolic syndrome subjects. *Significant difference between the INIT and the FINAL time point for that trial $(P<\mathbf{0 . 0 5})$. $†$ Significant difference between trials (HIIT vs CE) at that time point $(P<0.05)$. 
higher skin temperatures (i.e., index of a higher skin blood flow [9]) during HIIT versus CE may have resulted in a redistribution of blood volume peripherally, which together with the higher dehydration could have reduce central venous pressure increasing the drive for increase HR. Nevertheless, the reduction in workload during HIIT prevented cardiovascular strain and reduced $\mathrm{CO}$ and SV over time. SV reductions may limit the main cardiovascular adaptations to endurance training (i.e., increase in maximal SV), reducing the stimulus to enlarge end-diastolic volume (27).

It is known that $\mathrm{SV}$ plateaus at intensities more than $45 \%$ of $\dot{\mathrm{V}} \mathrm{O}_{2 \text { peak }}\left(\sim 55 \% \mathrm{HR}_{\mathrm{MAX}}\right)$ in sedentary subjects (5); thus, we expected similar SV in both trials because both exceed that intensity. To our surprise, SV during HIIT was lower than during CE trial (Fig. 5B). The technology we used for measuring $\mathrm{CO}\left(\mathrm{CO}\right.$; inert gas rebreathing method; Innocor $\left.{ }^{\circledR}\right)$ has been shown to be reliable (intraday $\mathrm{CV}=4 \%$ [11]) and fast enough to provide measures even during short bouts of highintensity exercise (12). However, it has also been shown to result in a lower value than the gold standard Fick method because of the recirculation of the inert gas into the pulmonary circulation (38). Thus, an underestimated value of $\mathrm{CO}$ obtained with this technology during the high bouts of HIIT could be responsible for the lower SV during that trial in comparison with the CE trial. Nevertheless, we sustain that

\section{REFERENCES}

1. Alberti KG, Eckel RH, Grundy SM, et al. Harmonizing the metabolic syndrome: a joint interim statement of the International Diabetes Federation Task Force on Epidemiology and Prevention; National Heart, Lung, and Blood Institute; American Heart Association; World Heart Federation; International Atherosclerosis Society; and International Association for the Study of Obesity. Circulation. 2009;120(16):1640-5.

2. Balady GJ, Arena R, Sietsema K, et al. Clinician's guide to cardiopulmonary exercise testing in adults: a scientific statement from the American Heart Association. Circulation. 2010;122(2):191-225.

3. Brouwer E. On simple formulae for calculating the heat expenditure and the quantities of carbohydrate and fat oxidized in metabolism of men and animals, from gaseous exchange (oxygen intake and carbonic acid output) and urine-N. Acta Physiol Pharmacol Neerl. 1957; 6:795-802.

4. Calbet JA, Gonzalez-Alonso J, Helge JW, et al. Cardiac output and leg and arm blood flow during incremental exercise to exhaustion on the cycle ergometer. J Appl Physiol (1985). 2007; 103(3):969-78.

5. Carrick-Ranson G, Hastings JL, Bhella PS, et al. The effect of lifelong exercise dose on cardiovascular function during exercise. J Appl Physiol (1985). 2014;116(7):736-45.

6. Cohen J. Statistical Power Analysis for the Behavioral Sciences. 2nd ed. Lawrence Erlbaum Associates; 1988.

7. Colin J, Timbal J, Houdas Y, Boutelier C, Guieu JD. Computation of mean body temperature from rectal and skin temperatures. J Appl Physiol. 1971;31(3):484-9.

8. Coyle EF, González-Alonso J. Cardiovascular drift during prolonged exercise: new perspectives. Exerc Sport Sci Rev. 2001;29(2):88-92.

9. Cheuvront SN, Kenefick RW, Montain SJ, Sawka MN. Mechanisms of aerobic performance impairment with heat stress and dehydration. J Appl Physiol (1985). 2010;109(6):1989-95. this underestimation in $\mathrm{CO}$ assessment remained constant during the entire HIIT trial and thus had no role on the reported reduction in $\mathrm{CO}$ from beginning to the end of the exercise.

In summary, in agreement with a previous report (25), we found that the traditional exercise bouts used to promote health (i.e., continuous moderate-intensity exercise) results in small power output reductions to maintain target HR, which do not reduce energy expenditure or $\mathrm{CO}$ during the workout. By contrast, an isocaloric bout of the increasingly popular HIIT results in significant reductions in power output, energy expenditure, and $\mathrm{CO}(21 \%, 15 \%$, and $10 \%$, respectively) to maintain the target HR. It could be speculated that exercise prescription based on HR target during HIIT will lower the expected training adaptations (metabolic and cardiovascular). However allowing HR and relative metabolic intensity to rise over time may result in increased thermal and cardiovascular strain, leading to fatigue and subject attrition.

The authors thank the volunteers for their dedication to the training. This work was partially funded by the Spanish Ministry of Economy and Competiveness (grant no. DEP-2014-52930-R). The authors state that the results of the study are presented clearly, honestly, and without fabrication, falsification, or inappropriate data manipulation. The results of the present study do not constitute endorsement by the American College of Sports Medicine. There are no conflicts of interest.

10. Church TS, Earnest CP, Skinner JS, Blair SN. Effects of different doses of physical activity on cardiorespiratory fitness among sedentary, overweight or obese postmenopausal women with elevated blood pressure: a randomized controlled trial. JAMA. 2007;297(19): 2081-91.

11. Fontana P, Boutellier U, Toigo M. Reliability of measurements with Innocor during exercise. Int J Sports Med. 2009;30(10):747-53.

12. Fontana P, Boutellier U, Toigo M. Non-invasive haemodynamic assessments using Innocor during standard graded exercise tests. Eur J Appl Physiol. 2010;108(3):573-80.

13. Fritzsche RG, Switzer TW, Hodgkinson BJ, Coyle EF. Stroke volume decline during prolonged exercise is influenced by the increase in heart rate. J Appl Physiol (1985). 1999;86(3):799-805.

14. Garber CE, Blissmer B, Deschenes MR, et al. American College of Sports Medicine Position Stand: quantity and quality of exercise for developing and maintaining cardiorespiratory, musculoskeletal, and neuromotor fitness in apparently healthy adults: guidance for prescribing exercise. Med Sci Sports Exerc. 2011;43(7): 1334-59.

15. Gibala MJ, Little JP, van Essen M, et al. Short-term sprint interval versus traditional endurance training: similar initial adaptations in human skeletal muscle and exercise performance. J Physiol. 2006;575(Pt 3):901-11.

16. Gilman MB. The use of heart rate to monitor the intensity of endurance training. Sports Med. 1996;21(2):73-9.

17. González-Alonso J, Mora-Rodríguez R, Below PR, Coyle EF. Dehydration reduces cardiac output and increases systemic and cutaneous vascular resistance during exercise. J Appl Physiol (1985). 1995;79(5):1487-96.

18. Gorman AJ, Proppe DW. Mechanisms producing tachycardia in conscious baboons during environmental heat stress. J Appl Physiol Respir Environ Exerc Physiol. 1984;56(2):441-6. 
19. Hagan RD, Upton SJ, Wong L, Whittam J. The effects of aerobic conditioning and/or caloric restriction in overweight men and women. Med Sci Sports Exerc. 1986;18(1):87-94.

20. Helgerud J, Høydal K, Wang E, et al. Aerobic high-intensity intervals improve $\dot{\mathrm{VO}}_{2 \max }$ more than moderate training. Med Sci Sports Exerc. 2007;39(4):665-71.

21. Jeukendrup A, VanDiemen A. Heart rate monitoring during training and competition in cyclists. $J$ Sports Sci. 1998;(16 Suppl):S91-9.

22. Kräuchi K, Wirz-Justice A. Circadian rhythm of heat production, heart rate, and skin and core temperature under unmasking conditions in men. Am J Physiol. 1994;267(3 Pt 2):R819-29.

23. Lucía A, Hoyos J, Pérez M, Chicharro JL. Heart rate and performance parameters in elite cyclists: a longitudinal study. Med Sci Sports Exerc. 2000;32(10):1777-82.

24. MacDougall JD, Hicks AL, MacDonald JR, McKelvie RS, Green HJ, Smith KM. Muscle performance and enzymatic adaptations to sprint interval training. J Appl Physiol (1985). 1998;84(6):2138-42.

25. Mikus CR, Earnest CP, Blair SN, Church TS. Heart rate and exercise intensity during training: observations from the DREW Study. Br J Sports Med. 2009;43(10):750-5.

26. Mora-Rodriguez R, Ortega JF, Hamouti N, et al. Time-course effects of aerobic interval training and detraining in patients with metabolic syndrome. Nutr Metab Cardiovasc Dis. 2014;24(7):792-8.

27. Neufer PD. The effect of detraining and reduced training on the physiological adaptations to aerobic exercise training. Sports Med. 1989;8(5):302-20.

28. Norton KH, Boushel R, Strange S, Saltin B, Raven PB. Resetting of the carotid arterial baroreflex during dynamic exercise in humans. J Appl Physiol (1985). 1999;87(1):332-8.

29. Ortega JF, Fernández-Elías VE, Hamouti N, Pallarés JG, MoraRodriguez R. Higher insulin-sensitizing response after sprint interval compared to continuous exercise. Int J Sports Med. 2015;36(3): 209-14.

30. Parkin JM, Carey MF, Zhao S, Febbraio MA. Effect of ambient temperature on human skeletal muscle metabolism during fatiguing submaximal exercise. J Appl Physiol (1985). 1999;86(3):902-8.

31. Périard JD, Cramer MN, Chapman PG, Caillaud C, Thompson MW. Cardiovascular strain impairs prolonged self-paced exercise in the heat. Exp Physiol. 2011;96(2):134-44.
32. Perri MG, Anton SD, Durning PE, et al. Adherence to exercise prescriptions: effects of prescribing moderate versus higher levels of intensity and frequency. Health Psychol. 2002;21(5):452-8.

33. Quanjer PH, Tammeling GJ, Cotes JE, Pedersen OF, Peslin R, Yernault JC. Lung volumes and forced ventilatory flows. Report Working Party Standardization of Lung Function Tests, European Community for Steel and Coal. Official Statement of the European Respiratory Society. Eur Respir J Suppl. 1993;16:5-40.

34. Ramanathan NL. A new weighting system for mean surface temperature of the human body. J Appl Physiol. 1964;19:531-3.

35. Rowell LB. Circulatory adjustments to dynamic exercise and heat stress: competing controls. In: Human Circulation: Regulation During Physical Stress. Oxford: University Press; 1986. pp. 363-406.

36. Rowell LB, Marx HJ, Bruce RA, Conn RD, Kusumi F. Reductions in cardiac output, central blood volume, and stroke volume with thermal stress in normal men during exercise. J Clin Invest. 1966;45(11):1801-16.

37. Sawka MN, Burke LM, Eichner ER, Maughan RJ, Montain SJ, Stachenfeld NS, et al. American College of Sports Medicine Position Stand: exercise and fluid replacement. Med Sci Sports Exerc. 2007;39(2):377-90.

38. Siebenmann C, Rasmussen P, Sørensen H, et al. Cardiac output during exercise: a comparison of four methods. Scand J Med Sci Sports. 2015;25(1):e20-7.

39. Skinner JS, Gaskill SE, Rankinen T, et al. Heart rate versus $\% \dot{\mathrm{VO}}_{2 \max }$ : age, sex, race, initial fitness, and training response-HERITAGE. Med Sci Sports Exerc. 2003;35(11):1908-13.

40. Tjønna AE, Lee SJ, Rognmo Ø, et al. Aerobic interval training versus continuous moderate exercise as a treatment for the metabolic syndrome: a pilot study. Circulation. 2008;118(4):346-54.

41. Trinity JD, Pahnke MD, Lee JF, Coyle EF. Interaction of hyperthermia and heart rate on stroke volume during prolonged exercise. J Appl Physiol (1985). 2010;109(3):745-51.

42. Wingo JE. Exercise intensity prescription during heat stress: a brief review. Scand J Med Sci Sports. 2015;25(1 Suppl):90-5.

43. Wingo JE, Cureton KJ. Maximal oxygen uptake after attenuation of cardiovascular drift during heat stress. Aviat Space Environ Med. 2006;77(7):687-94.

44. Wingo JE, Salaga LJ, Newlin MK, Cureton KJ. Cardiovascular drift and $\mathrm{VO}_{2 \max }$ during cycling and walking in a temperate environment. Aviat Space Environ Med. 2012;83(7):660-6. 


\section{AUTHOR QUERY}

\section{AUTHOR PLEASE ANSWER QUERY}

AQ1 2 Please check if authors name are correctly captured for given names (in red) and
surnames (in blue) for indexing after publication. END OF AUTHOR QUERY 